This study uses data from a random survey of 2001 Michigan households to analyze the extent to which the Michigan circuit-breaker has been successful in reducing the income regressivity of the property tax and in changing relative property tax burdens. Because of its relatively extensive coverage, including renters as well as homeowners and the nonaged as well as the aged, the circuit-breaker has yielded a more equal distribution of income within Michigan. Its potential to change the distribution of income depends on the particular formula utilized, but redistributional effects have thus far been limited because program participation has been positively correlated with income. To the extent that reductions in the price of public services created by the circuit-breaker are perceived by households, the biggest stimulus appears to be in high property tax/high-income counties.

\title{
THE DISTRIBUTIONAL IMPACT \\ OF STATEWIDE PROPERTY \\ TAX RELIEF: THE MICHIGAN CASE
}

\author{
DANIEL L. RUBINFELD
}

University of Michigan

MICHAEL J. WOLKOFF

University of Rochester

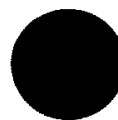

During the past two decades 29 states have responded to voter dissatisfaction with rising property taxes by instituting circuit-breakers to provide property tax relief (ACIR, 1979). In so doing, they have changed both the incidence of the property tax and tax price of local governmental services. In this article we utilize survey data to investigate the distributional consequences of statewide property tax relief with reference to the Michigan circuit-breaker.

Earlier work on the circuit-breaker focused on whether current or permanent income was the proper measure by which to

\footnotetext{
AUTHORS'NOTE: The authors wish to thank Harvey Brazer, Edward Gramlich, Helen Ladd, James Reschovsky, and Robert Vishny for their helpful guidance and suggestions.
}

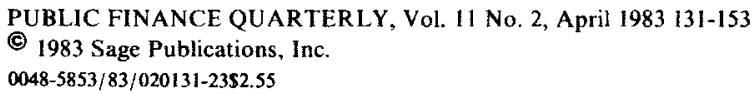


evaluate redistributive effects (Aaron, 1974), as well as the design aspects of the circuit-breaker: Should benefits be awarded after a tax threshold is reached or on a sliding scale? (ACIR, 1975; Gold, 1976). However, data limitations restricted substantially the empirical detail of the analyses. This study fills in some of the informational gaps resulting from these data limitations, while asking whether the Michigan circuit-breaker has been successful in reducing the income regressivity of the property tax and in changing relative property tax burdens.

The second section of this article provides the background for understanding property tax circuit-breakers. The survey data set is used to describe the benefit distribution of the Michigan circuitbreaker program within income, age, and homeownership categories. These results are presented for taxpayers who have taken advantage of the program and those who could have taken advantage of it. This comparison offers some indication of the percentage of households by category who participate in the tax relief program.

The third section presents two measures: one for evaluating the income distributional effect of the circuit-breaker and the other for describing the distribution of property tax credits. These measures are used to summarize the results of a series of simulations that evaluate changes in each of three key parameters in the Michigan circuit-breaker formula. We show how to find a circuit-breaker schedule that meets the objective of proportionality in the property tax system, and we test its success in reaching that goal.

The final section of this article examines the differential effect the circuit-breaker has on the tax prices for local public services facing Michigan voters. The analysis indicates that the pattern of tax price changes may very well run counter to the local spending behavior that the state might want to encourage. On balance we find that the circuit-breaker, as currently administered, is not successful. It achieves neither an equity goal by substantially altering the distribution of income nor a political goal by leading to widespread household perceptions of lower property tax payments. The analysis does make clear, however, that some 
changes in the circuit-breaker formula, and in the way it is administered, can move the program much closer to the previously stated economic and political objectives.

\section{THE MICHIGAN CIRCUIT-BREAKER}

\section{THE DATA SET}

Our analysis of the Michigan property tax circuit-breaker uses survey data collected in November and December 1978. The survey questionnaire was administered by the University of Michigan Institute for Social Research using telephone interviews of approximately 20 minutes in length. The survey itself involved a random sample of 2001 Michigan households.

The survey was conducted shortly after the November 1978 election, an election characterized by the presence of three tax limitation proposals on the ballot. Their presence, and the consequential discussion focusing on state and local governmental tax and expenditure behavior, brought tax and service-level issues directly to the voters' attention. Respondents were questioned about family income, house value, property tax payments, homeownership status, and whether they had filed for the circuitbreaker on their last income tax return. ${ }^{1}$ The responses were of sufficient detail to allow us to calculate estimated individual circuit-breaker refunds by simulating respondent participation in the actual ongoing state program or in variants of that program. ${ }^{2}$ The data set also allowed us to study those individuals not receiving benefits who were eligible for the program.

\section{THE PROGRAM}

The Michigan circuit-breaker provides an income tax credit to all property taxpayers who qualify regardless of their age, income, or homeownership status. Program benefits are determined using a threshold formula (see ACIR, 1975), which defines an acceptable property tax burden as being $3.5 \%$ of household 
income. Specifically, for most filers, the circuit-breaker credit is calculated using the following formula:

$$
\begin{aligned}
R & =.6^{*}\left(T-.035^{*} Y\right) & & \text { if } T>.035^{*} Y \\
& =0 & & \text { if } T \leqslant .035^{*} Y \\
R & \leqslant \$ 1200 & &
\end{aligned}
$$

where $\mathrm{R}=$ state personal income tax credit

$\mathrm{T}=$ local property tax liabilities

$\mathrm{Y}=$ income (from all sources)

Senior citizens, the handicapped and blind, some veterans, and farm owners face more generous formulas, although the largest rebate any filer can receive is restricted to $\$ 1200$.

Renters use the same formula as homeowners. The state assumes that $17 \%$ of the rent paid goes to property taxes, so that renters substitute $.17^{*}$ (Rent) for T when calculating their credit. ${ }^{3}$ Both renters and homeowners receive, as a credit, $60 \%$ of the tax payment in excess of the threshold. Senior citizens are treated more generously. Property taxes paid in excess of the $3.5 \%$ threshold are rebated in full. Senior citizens with incomes below $\$ 6000$ face an even more generous formula since the tax burden threshold is set at a percentage of family income that ranges from 0 to $3.0 \%$ depending on income.

Taxpayers must file a separate form with their Michigan State Income Tax returns in order to receive the circuit-breaker refund. While this undoubtedly eases the administrative task of running the circuit-breaker program, it results in two unintended consequences that have important policy implications. First, those who do not file state income tax returns will not receive property tax credits, and second, tying the property tax rebate to the state income tax return obfuscates one economic impact of this type of tax relief the reduction of local tax burdens. Taxpayers are likely to view the circuit-breaker as an income tax refund rather than as a reduction in local property taxes.

Despite the need to file the income tax form, over $1,150,000$ Michigan taxpayers received a total of over $\$ 280,000,000$ in program benefits in 1977.4 


\section{DATA COMPARABILITY}

We can get a rough sense of the reliability of our data set by comparing selected sample summary measures with data obtained by the Michigan State Treasury Department (based on a $10 \%$ sample of 1977 returns). We should note, first, that the state data are taken from individual returns and thus exclude information about nonfilers. Thus the state data provide no information about those who are eligible but who failed to file for a tax credit. Our analysis is based on 1772 observations of individuals who provided sufficient information for us to obtain an estimate of their property tax credit.

In 1977 the State of Michigan estimated the average credit paid to those successfully filing for credits as \$249. Our data suggest that if all eligible individuals did file, their average payments would be $\$ 237,5 \%$ less. In fact, we calculate that $53 \%$ of the sample should receive a circuit-breaker credit, while only $33.8 \%$ actually did receive credits according to the state. The evidence of limited participation in the program, in the $60 \%$ range, is quite clear. Because the state looks only at those claiming credits, and we look at those eligible, further direct comparisons are not fruitful. Our attempt to make a more direct comparison by asking respondents directly whether they filed for a property tax credit was not fully successful because some of those stating that they did file were not eligible by our calculations. ${ }^{5}$ For this reason, we continue our analysis focusing primarily on all eligible participants. We do, however, use the direct response about participation in the following section to obtain some sense of the correlation between participation and age, income, and homeownership.

\section{PROGRAM BENEFITS}

In this subsection we discuss how the circuit-breaker credits are distributed, focusing on income, age, and homeownership status. We contrast this with the characteristics of the sample as a whole and with the potential distributional impacts of a program in which all eligible residents participate. 
TABLE 1

Estimated Distributional Impact of the Circuit-Breaker

(i) \% Distribution of Individuals by Income Class

\begin{tabular}{|c|c|c|c|c|c|}
\hline & $\$ 0-\$ 8,000$ & $\$ 8,000-\$ 14,000$ & $\$ 14,000-\$ 20,000$ & $\$ 20,000-\$ 26,000$ & $\geq \$ 26,000$ \\
\hline $\begin{array}{l}\text { Entire Sample } \\
\qquad(\mathrm{N}=1772)\end{array}$ & $18.7 \%$ & $19.0 \%$ & $20.2 \%$ & $20.6 \%$ & $21.5 \%$ \\
\hline $\begin{array}{l}\text { Those Who Stated } \\
\text { That They Filed } \\
(\mathrm{N}=765)\end{array}$ & ed & 16.9 & 21.4 & 23.5 & 27.1 \\
\hline $\begin{array}{l}\text { Those Eligible } \\
\text { To Receive } \\
\text { Credit } \\
\qquad(N=949)\end{array}$ & 30.6 & 19.0 & 17.6 & 17.9 & 15.0 \\
\hline \multirow[t]{2}{*}{ (ii) } & istribution & of Sample by Age & $\%$ Distribu & bution by Homeown & rstip \\
\hline & $\leq 65$ & $\geq 65$ & & Owns & Rents \\
\hline Entire Sample & $89.1 \%$ & $10.9 \%$ & Entire Sample & $72.3 \%$ & $26.7 \%$ \\
\hline Filers & 91.6 & 9.4 & Filers & 90.8 & 8.9 \\
\hline Those Eligible & 84.2 & 15.8 & Those Eligible & 76.4 & 23.6 \\
\hline
\end{tabular}

Although the state sample illuminates the distribution of program benefits for those actually receiving circuit-breaker rebates, it tells us nothing about how this distribution would compare with the distribution resulting were all eligible households to take advantage of the program. Table 1 summarizes the distribution of program participants in three categories: for our entire sample, for those within our sample who stated that they filed for the circuit-breaker, and for those who we estimate would receive property tax rebates whether they filed or not.

Although the results differ by whether they focus on income age, or ownership status, they concur on two important points. First, the distribution of individuals by each characteristic in the sample differs substantially from the distribution of those taking advantage of the program. Second, the distribution of those taking advantage of the program differs from those who could take advantage.

While the program design may have never incorporated neutrality as an objective, the actual implementation does have 
distributional consequences. For instance, panel i of Table 1 reveals that although $18.7 \%$ of the sample have family income below $\$ 8000$, only $11 \%$ of those who report filing for the circuitbreaker were in this income class. Of course, such an outcome might be consistent with a very low income elasticity of demand for housing. However, most income elasticity estimates are not especially low, and our estimates of those who qualified for the program lead to a different conclusion (see Polinsky and Ellwood, 1979). By our calculations, over $30 \%$ of those who could take advantage of the program are in the lowest income class. In contrast, the percentage of high-income respondents stating that they filed for the circuit-breaker exceeds the proportion that qualified to receive rebates (and also exceeds the proportion of upper-income individuals in the sample as a whole). The data clearly suggest a high participation rate among high-income households. The result is that, because of limited participation, a program that would have had some redistributional effect may operate in the opposite direction. ${ }^{6}$

A similar story can be told for homeowners and renters. Despite provision for renters in the circuit-breaker formula, renters participate in the program to a much smaller extent than do homeowners. If, however, we look at who is eligible for circuit-breaker credits, we see that those who qualify under the present state formula are in line with the actual distribution of homeowners and renters in our sample.

Table 1 deals only with the percentage of beneficiaries and not with the distribution of benefits. It is conceivable that the benefit distribution to filers is similar to the distribution of all eligible households. Panel $\mathrm{i}$ of Table 2 examines this question for different income classes in the sample. The distribution of dollars between income classes also changes depending on whether we restrict our examination to those who claim to have filed for the credit or whether we look at all those in the sample who we determine to be eligible. The income redistributional consequences are muted, however, because while eligibility for rebates is progressive in incidence, larger rebates go to higher-income individuals (see panel ii of Table 2 , line 3 ). 
TABLE 2

Survey Estimated Distribution of Credits

(i) Percent Distribution of Dollar Credits by Income Class

\begin{tabular}{|c|c|c|c|c|c|}
\hline & $\$ 0-\$ 8,000$ & $\$ 8,000-\$ 14,000$ & $\$ 14,000-\$ 20,000$ & $\$ 20,000-\$ 26,000$ & $\geq \$ 26,000$ \\
\hline Entire Sample & $29.5 \%$ & $16.3 \%$ & $16.4 \%$ & $20.3 \%$ & $17.5 \%$ \\
\hline $\begin{array}{l}\text { Stated Fil } \\
\text { Yes }\end{array}$ & 20.0 & 20.3 & 18.8 & 23.1 & 17.7 \\
\hline
\end{tabular}

(ii) Average Dollar Credit by Income Class

\begin{tabular}{|c|c|c|c|c|c|}
\hline & $\$ 0-\$ 8,000$ & $\$ 8,000-\$ 14,000$ & $\$ 14,000-\$ 20,000$ & $\$ 20,000-\$ 26,000$ & $\$ 26,000$ \\
\hline Entire Sample & $\$ 200$ & $\$ 109$ & $\$ 103$ & $\$ 125$ & $\$ 103$ \\
\hline $\begin{array}{l}\text { Stated Piling } \\
\text { Yes }\end{array}$ & 290 & 194 & 142 & 158 & 106 \\
\hline $\begin{array}{l}\text { Eligible for } \\
\text { Credit }\end{array}$ & 229 & 203 & 221 & 269 & 277 \\
\hline
\end{tabular}

Overall, we find that within our sample the distribution of benefits to those who file for the circuit-breaker differs relatively little by income class from the original roughly equal allocation of individuals to income classes (see panel i of Table 1, row 1). This occurs despite the low participation rates of the lowest-income individuals, because average benefits are so much higher than for other income classes. When all in our sample who are eligible are included in the program, there is a sizable transfer to the lowest income class, but the transfer is muted somewhat because larger average credits for this category go to higher income individuals. In both cases, the effects upon the midrange income classes are minor.

It is hard to summarize broadly all of the previous results, but what is clear is that the current program can and does have different effects depending on the level of participation in the program. In the next section of this article, we assume full participation - that all who are eligible will take advantage of a circuit-breaker program as a basis for comparing different circuit-breaker formulas and for determining the potential redistribution achievable. 


\section{THE DISTRIBUTIONAL EFFECTS OF THE CIRCUIT-BREAKER}

A clear consensus does not exist as to which distributional objectives should be met by the circuit-breaker. Grubb and Hoachlander (1978), for example, argue that the primary goal is to measure the income distributional effects and the tax benefit minimizing dislocation costs. Other economists and politicians have focused more directly on the objective of reducing property tax burdens whatever the final incidence on income (see Shroeder and Sjoquist, 1978).

In this article we develop two summary measures that allow us to measure the income distributional impacts and the tax benefit distribution of a series of simulated circuit-breaker program reforms. We chose the first measure as an indicator of the program's ability to achieve an equity goal of a more progressive income distribution, and the second as an indicator of the success of the political goal of reducing tax burdens of high property taxpayers. In doing so, however, we make no normative judgment as to the importance of either of the measures. Nor are we in a position to discuss or analyze the difference between distributional effects measured in terms of current income as opposed to permanent income.

To focus on the income regressivity of the property tax, we calculate the income elasticity of the ratio of property taxes paid net of circuit-breaker rebates to income. Specifically, the elasticity $\theta$ is defined as follows:
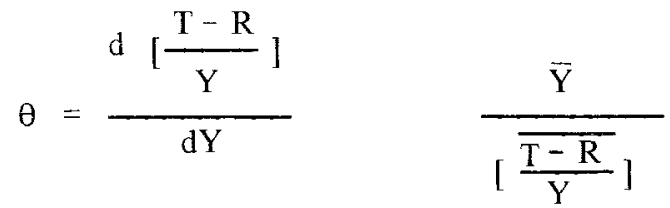

where $T$ represents reported property taxes paid (annually), $\mathrm{Y}$ is family income, and $R$ is our calculated estimate of rebates that would be paid were all eligible individuals to avail themselves of the program. By using all eligible applicants we are able to calculate the potential distributional effects of a given program. $\theta$ is calculated from a multiple regression in which all individual 
respondents are included in the sample. We have chosen to specify a linear form with the elasticity calculated at the mean to avoid distortions that arise (for low-income individuals) when a constant elasticity formulation is used. $\Theta$ has the property of being equal to 0 when property taxes paid (net of rebates) are proportional to income, greater than 0 when the system is progressive, and less than 0 when the system is regressive.

Under the current Michigan circuit-breaker formula we calculate $\theta$ to be -.176 for homeowners and -.663 for renters, implying that the current property tax system (with the circuitbreaker) is regressive. ${ }^{8}$ When $\mathrm{R}=0$, we find -.366 for homeowners and -.999 for renters, so that the current circuit-breaker system has clearly affected the income regressivity of the property tax. If the goal is to make the property tax system proportional, we would need to find a circuit-breaker formula that made $\theta$ approximately equal to zero.

Our second evaluation measure is the income elasticity of the ratio of tax rebates to total property taxes paid. This elasticity, denoted $\Psi$, is defined as follows:

$\psi=\frac{d[R / T]}{d Y} \quad \frac{\bar{Y}}{\overline{[R / T]}}$

Once again the elasticity is determined from a multiple regression and evaluated at the point of means. $\Psi$ describes the pattern of changes in rebates or tax credits by income. Thus it has more to say about the political consequences of a program change than about overall income distribution. An elasticity of zero implies that the ratio of rebates to taxes is independent of income, while a negative elasticity implies that the ratio of rebates to taxes falls as income rises. Other things equal, the more negative the value of $\Psi$, the greater the percentage reduction in property tax payments received by those with low rather than high incomes. For the current Michigan system we calculate $\Psi$ to be -.592 for homeowners and -1.136 for renters.

Now we are in a position to discuss possible reforms of the circuit-breaker formula. Initially, we maintain the existing structure, but change selected formula parameters. ${ }^{9}$ To generalize the 


\section{TABLE 3}

Simulated Distributional Impact and Costs of Selected Changes in the Michigan Formula

\begin{tabular}{|c|c|c|c|c|c|}
\hline Policy Instrument & $\theta$ Own & $\theta$ Rent & $\Psi 0 \mathrm{wn}$ & $\psi \operatorname{Rent}$ & Cost Index \\
\hline Status quo ${ }^{a}$ & -.176 & -.663 & -.592 & -1.136 & 1.000 \\
\hline$p=.025$ & -.185 & -.664 & -.391 & -.949 & 1.435 \\
\hline$p=.045$ & -.180 & -.672 & -.767 & -1.22 & .733 \\
\hline$r=.4$ & -.212 & -.785 & -.654 & -1.162 & .766 \\
\hline$r=.8$ & -.135 & -.489 & -.558 & -1.112 & 1.218 \\
\hline$r=1.0$ & -.099 & -.225 & -.532 & -1.107 & 1.426 \\
\hline$L=600$ & -.205 & -.669 & -.599 & -1.135 & .900 \\
\hline $\mathrm{L}=1800$ & -.176 & -.657 & -.587 & -1.138 & 1.029 \\
\hline$p=.045, r=1.0$ & -.114 & -.294 & -.714 & -1.211 & .975 \\
\hline$r=0.8, L=600$ & -.178 & -.500 & -.575 & -1.119 & 1.053 \\
\hline$r=r(V)^{C}$ & -.084 & -.223 & -.780 & -1.139 & .963 \\
\hline$r=r(Y)^{d}$ & -.081 & -.345 & -.784 & -1.123 & 1.055 \\
\hline $\mathrm{D}=\mathrm{p}(\mathrm{Y})^{\mathrm{d}}$ & -.108 & -.615 & -.861 & -.984 & .902 \\
\hline
\end{tabular}

a. Initially $r=.6, p=.035, L=1200$.

b. Ratio of cost of reform to cost of current program, assuming full participation.

c. Step function.

d. Revised step function.

current circuit-breaker formula, let $\mathrm{r}$ represent the reimbursement rate (.6 currently), $\mathrm{p}$ equal the threshold percentage $(.035$ in this case), and $\mathrm{L}$ equal the maximum rebate attainable $(\$ 1200$ in this case). Table 3 summarizes the results of a number of simulations in which each of the parameters $r, p$, and $L$ were allowed to vary individually, with the remaining parameters set at their initial values.

First consider the possibility of changing the threshold percentage, $p$. The overall income distribution effects of any change in $p$ are quite small for both renters and homeowners ( $\theta$ changes only slightly). This reflects, in part, the fact that as the threshold percentage is decreased, the limit of $\$ 1200$ comes into effect more frequently for those in the lower half of the income distribution and mutes any possibility of substantial redistribution. Despite 
the insensitivity of the summary measures there is some redistribution among income classes that is important. If we were to divide all households into five roughly equal income classes, as is done in the second section of this article, we would find that an increase in the threshold proportion from .025 to .045 substantially increased the share of tax rebates received by the lowest income class (from $22 . \%$ to $37.4 \%$, with the current share [ $p=.035]$ being $29.5 \%$ ). The second lowest income class increased its share slightly, while all other classes received smaller proportions as the threshold rate increased. What has happened, of course, is that the increase in the threshold level reduces program eligibility primarily for taxpayers with relatively high incomes. This reduction substantially outweighs the reduction in eligibility for individuals with low incomes. However, since the total number of individuals participating under the program with a high threshold level is reduced, and because the higher threshold reduces benefit levels for everyone below the cap, there is very little overall income distributional impact.

The effect on relative tax reduction is quite important, however it is measured. The change in the distribution of rebates by income class is reflected here as a sharp decline in $\Psi$ as p rises. This tells us that those with low incomes receive relatively greater percentage tax reductions than do those with high incomes. In fact, the relative benefits to the poor can be increased by increasing $\mathrm{p}$, which saves substantially on program cost. However, absolute benefits fall for all income classes, so an increase in p can only be motivated by a desire to save costs without substantial adverse distributional effects. Put somewhat differently, a decrease in $\mathrm{p}$ is not a very good policy change because (a) it does little to affect the overall income distributional impact of the circuitbreaker, (b) it increases the relative benefits received by those with high incomes, and (c) it is extremely costly.

Now consider the impact of a change in the reimbursement rate r. Here the income distributional impact is substantial. An increase in the reimbursement rate substantially decreases the regressivity of the property tax for both homeowners and renters. While full reimbursement does not make the property tax system 
proportional, it appears that a program that combined full reimbursement with a lower threshold percentage could come closer to this goal. The cost of such a program would not be trivial, since $42.6 \%$ added cost is associated with full reimbursement alone. Not surprisingly, changing $\mathrm{r}$ has little effect on $\psi$. Since $\mathrm{p}$ is fixed, there is no change in who is eligible for the program and only the maximum rebate limit of $\$ 1200$ affects the value of $\Psi$. In particular, as the reimbursement rate increases, the limit comes into effect for more individuals (especially those with low to middle incomes) so that the rebate rate elasticity becomes less pro-poor.

In order to see how a combination of changes might improve distribution without adding much additional cost, we simulated the effect of a plan with $p=.045$ and $r=1.0$. Such a plan would reduce the costs of the present circuit-breaker formula by $2.5 \%$ and in so doing would provide substantial redistributive benefits. While this precise formulation does not meet the objective of making the property tax proportional it does move in that direction. $\theta$ for both homeowners and renters is less regressive than in any other simulation expect the relatively expensive plan of $p=.035$, and $\mathbf{r}=1.0$. Our estimates of $\Psi$ indicate that the distribution of rebates is also relatively pro-poor.

Finally, consider the effect of a change in the rebate limit, currently at $\$ 1200$. The effects are really quite small across the board, with the only substantial measured change being an increase in the income regressivity of the property tax (net of rebates) when the limit is reduced to $\$ 600$. While the cost savings of such a reduction are not large (in the order of $10 \%$ ), our analysis suggests that by enforcing a lower limit some money could be saved that could "better" be spent on an increased reimbursement rate. To test this, we simulated the effect of a reform with a reimbursement rate of .8 and a limit of $\$ 600$. We found that this program change had very little to offer in the way of redistributional benefits. In fact, homeowners with low incomes were found to be slightly worse off than with the original program, and in general the elasticity of tax rebates indicates a more regressive structure. 
If either of the two distributional objectives is to be achieved at minimum cost, it is clear that more substantial changes in the circuit-breaker formula must be incorporated. ${ }^{10}$ The obvious way to do so is to make each of the three policy parameters a function of income. We use a simple step function to achieve this objective and to minimize administrative problems. To illustrate such a change we have simulated the effects of a reform in which we allow the reimbursement rate to vary inversely with income as follows:

$$
\begin{array}{lll}
r=1.0 & \text { if } & 0 \leqslant Y \leqslant \$ 8000 \\
r=0.8 & \text { if } & 8000<Y \leqslant 14,000 \\
r=0.6 & \text { if } & 14,000<Y \leqslant 20,000 \\
r=0.4 & \text { if } & 20,000<Y \leqslant 26,000 \\
r=0.2 & \text { if } & 26,000<Y
\end{array}
$$

Under such a reform the property tax net of rebates becomes nearly proportional for homeowners and substantially less regressive for renters. At the same time there is relatively little change in the rebate rate elasticities. Note that this particular simulated reform actually costs $4 \%$ less than the current Michigan system.

The example makes it clear that allowing the policy parameters to vary with income can have a sizable impact on distribution. Thus while simplification of structure may be politically desirable, it is not the most effective way of altering the income distribution. Focusing on the continuous analogoue of the previous step function we can utilize the data to find a formula that guarantees that proportionality will be achieved." ${ }^{1}$ In this more general formulation we let $r$ and $p$ be functions of income, $Y$, but assume that either no rebate limit exists or that it is sufficiently large to have little effect on any redistribution attainable. In this case the rebate formula becomes

$$
\mathrm{R}=\mathrm{r}(\mathrm{Y})[\mathrm{T}-\mathrm{p}(\mathrm{Y}) \mathrm{Y}]
$$

where $\mathrm{R}$ is the dollar amount of the rebate. A proportional tax net of rebate is one in which $d[(T-R) / Y] / d Y$ equals 0 . Notice that 
the derivative is proportional to $\theta$, the income elasticity of the ratio of net property taxes to income. The first-order condition that is sufficient to achieve proportionality is as follows:

$$
\begin{array}{r}
d(T / Y) / d Y=(T / Y)\left(-r^{\prime}(Y)\right)+(1-r(Y))[d(T / Y) / d Y]+r(Y) p^{\prime}(Y) \\
+p(Y) r^{\prime}(Y)=0
\end{array}
$$

In general there are an infinite combination of $r(Y)$ and $p(Y)$ that will solve the equation, so we simplify by asking whether there exists an $\mathrm{r}(\mathrm{Y})$ that works when $\mathrm{p}$ is constant, and then whether there is a $p(Y)$ that works when $r$ is constant.

First consider the case in which $p$ is constant. The solution to the differential equation implicit in equation 4 is as follows:

$$
r(Y)=1-K /[Q(Y)-p]
$$

where $K$ is a constant of integration and $Q(Y)=d[(T / Y) / d Y]$. The constant of integration is arbitrary and can be chosen to minimize the cost of the program. p, of course, is given and fixed, and $Q(Y)$ can be determined by running a regression of $T / Y$ as a function of $\mathrm{Y}$ (either linear or a polynomial is likely to do). For example, we estimated the following quadratic function ( $\mathrm{t}$ statistics in parentheses).

$$
\mathrm{T} / \mathrm{Y}=\underset{(10.1)}{.11-.342 \times 10^{-5} \mathrm{Y}+.288 \times 10^{-7} \mathrm{Y}^{2}} \quad \mathrm{R}^{2}=.09
$$

We then evaluated $Q(Y)$ for the midpoints of each of the five income classes, and chose that value of $K$ that resulted in a reimbursement rate of 0 for the highest income class. This reduces costs at the expense of being unable to achieve full redistribution within the highest class. In fact, we found that with $\mathrm{p}$ chosen to be .035 , and a limit of $\$ 1200$, there is no solution for $r(Y)$ that can achieve full proportionality without allowing the reimbursement rate to be negative for those with high incomes or greater than $100 \%$ for those with low incomes. Without the limit L, a lower 
vale of $\mathrm{p}$ is likely to be more successful. Even though we could not achieve full proportionality with p equal to .035 , we reestimated the circuit-breaker using a rebate schedule derived in the manner described above. We can see from Table 3 that equity is improved considerably over the present program with only $5 \%$ greater costs. However, our fine tuning does not yield a result much different than does the use of a simple step function, which is even less expensive.

We then held $\mathrm{r}$ constant and solved for $\mathrm{p}$, with the following solution:

$$
\mathrm{p}(\mathrm{Y})=\mathrm{Q}(\mathrm{Y})[(\mathrm{r}-1) / \mathrm{r}]+\mathrm{K}
$$

Using the same formula for $\mathrm{Q}(\mathrm{Y})$ as before and choosing a value for $\mathrm{K}$ to limit the cost of the program, we simulated this reform, keeping the $\$ 1200$ limit in place. Because of the large effect on program cost of setting the threshold too low we were forced to constrain our schedule so that not everyone from each income class would be eligible. We found that while equity was improved, changes in $\mathrm{p}$ did not have major impacts on our distributional measures. ${ }^{12}$ Again we found that there is a highly complex interaction between the three parameters and that without simulating the various program reforms, it is not possible to tell precisely what the distributional and cost effects will be.

\section{OTHER EFFECTS OF THE CIRCUIT-BREAKER}

In addition to its distributional effects the circuit-breaker may influence household behavior. For one, a more generous formula can reduce the after-tax price of housing, thus encouraging greater housing consumption. Second, circuit-breakers may encourage the use of property taxes rather than user charges, when the latter may be more efficient in the sense of more closely approximating a benefits tax. (Of course, the federal income tax deductibility of property taxes may do this as well.) In addition, circuit-breakers may reduce the work incentives of low-income 
households, although in Michigan the credit for city income taxes paid goes in the other direction. A fourth effect is that circuitbreakers may alter the level of support of individuals in the population for property tax increases and thus increase the level of public services provided.

Whether increased expenditures are desirable or not depends, of course, on whether one believes that current service levels are proper. If one were to argue that the level of services provided by the median voter ${ }^{13}$ understates the socially desirable level of services because of the presence of positive beneficial externalities (e.g., in education) a program that lowers tax prices (measured as the cost to a household of financing an additional \$1 per capita of local expenditures) and stimulates public spending may improve social welfare.

To get a rough sense of the order of magnitude of the effect of the circuit-breaker, we assumed that the circuit-breaker reduces tax price but has no measurable effect on household income and no impact on the decision to migrate to a new jurisdiction. We then calculated the mean tax prices for individuals in Michigan by county of residence under the assumption that no circuit breaker benefits were perceived. We also recalculated these statistics under the assumption that all individuals perceived the benefits of the current system, as well as a number of reforms suggested earlier. The results are summarized in Table $4 .{ }^{14}$ We might note first that the circuit-breaker brings about an overall reduction in tax price of $30 \%$, a substantial change. If the price elasticity of demand for public services were equal to -1 , for example, the circuit-breaker could lead to an approximately $30 \%$ increase in the level of public spending. Even for a much smaller elasticity the effect can be substantial. ${ }^{15}$

It is important to realize, however, that individual voters may not perceive the price reduction as such. There is some preliminary evidence that supports this view; Rubinfeld (1977) found that voters in a local school election in Troy, Michigan, did not respond to the circuit-breaker, and similar results were found by Gramlich and Rubinfeld (1982). Of course, voter perceptions may change over time as information improves, so that our $30 \%$ 
TABLE 4

The Effect of the Circuit-Breaker on Tax Price

\begin{tabular}{|c|c|c|c|c|c|c|}
\hline$\frac{\text { County }}{(1)}$ & $\frac{\mathrm{N}}{(2)}$ & $\begin{array}{l}\begin{array}{l}\text { Mean Family } \\
\text { Income }\end{array} \\
(3)\end{array}$ & $\begin{array}{c}\text { Tax Base/ } \\
\text { Capita }\end{array}$ & $\begin{array}{l}\text { No Credit } \\
\text { Tax-Price } \\
(5)\end{array}$ & $\begin{array}{l}\text { Tax Price } \\
\text { with Credit }\end{array}$ & $\frac{\text { Ratio }}{(6) /(5)}$ \\
\hline Allegan & 29 & $\$ 5068$ & $\$ 5554$ & 7.30 & 5.02 & .69 \\
\hline Bay & 42 & 6116 & 6496 & 4.64 & 2.85 & .61 \\
\hline Berrien & 31 & 6003 & 6452 & 4.55 & 3.70 & .81 \\
\hline Branch & 26 & 5660 & 6079 & 5.80 & 4.14 & .71 \\
\hline Charlevoix & 23 & 5160 & 10223 & 2.51 & 1.92 & .76 \\
\hline Chippewa & 31 & 4620 & 4349 & 5.80 & 4.29 & .74 \\
\hline Genesee & 31 & 7223 & 5865 & 5.24 & 4.02 & .77 \\
\hline Ingham & 81 & 6855 & 5373 & 5.42 & 3.69 & .68 \\
\hline Ionia & 29 & 4912 & 4419 & 5.95 & 5.09 & .86 \\
\hline Jackson & 51 & 6268 & 3451 & 7.92 & 6.41 & .81 \\
\hline Kalamazoo & 50 & 6888 & 5895 & 5.35 & 4.00 & .75 \\
\hline Kent & 81 & 6373 & 5644 & 4.43 & 3.46 & .78 \\
\hline Macomb & 140 & 7267 & 6621 & 4.80 & 3.12 & .65 \\
\hline Marquette & 30 & 5572 & 5524 & 3.90 & 3.44 & .88 \\
\hline Midland & 45 & 7044 & 9141 & 4.33 & 3.25 & .75 \\
\hline Monroe & 43 & 6082 & 8026 & 5.88 & 4.18 & .71 \\
\hline Oakland & 199 & 8619 & 7779 & 5.68 & 3.85 & .68 \\
\hline St. Clair & 58 & 5913 & 6973 & 5.32 & 3.62 & .68 \\
\hline Shiawasee & 27 & 5904 & 3318 & 5.32 & 4.88 & .92 \\
\hline Wayne & 420 & 7315 & 4569 & 4.75 & 3.45 & .73 \\
\hline Overal1 $^{\mathrm{d}}$ & 2001 & 6643 & 6007 & 5.01 & 3.64 & .70 \\
\hline
\end{tabular}

a. Counties listed include only those with 20 or more observations.

b. We define tax price in text. A more accurate definition would incorporate the individual's federal marginal tax bracket, the reliance of the locality on property taxes, the matching rate of intergovernmental grants, the "flypaper effect," and the extent to which industrial and commercial property share the tax burden.

c. Tax Price with Credit is calculated on the assumption that only those who claimed to have filed for a credit actually perceive a price reduction. The price reduction would be greater were we to measure the potential impact of the program.

d. The row stating overall results is calculated as the mean of all individual observations for the entire survey.

provides an upward bound for future circuit-breaker-induced public spending increases.

It is also clear from Table 4 that the magnitude of the price reduction varies from county to county (from a lower-bound ratio of .61 to a high of .92 ). The overall pattern is not all that 
TABLE 5

Correlations Between Macro (Micro) Policy Variables

\begin{tabular}{|c|c|c|c|c|}
\hline & Income & $\begin{array}{l}\text { Tax Base } \\
\text { per capita }\end{array}$ & $\begin{array}{c}\text { Expenditures } \\
\text { per capita }\end{array}$ & $\begin{array}{l}\text { Tax-Price } \\
\text { with Credit }\end{array}$ \\
\hline $\begin{array}{l}\text { Tax Base per } \\
\text { Capita }\end{array}$ & $\begin{array}{l}-.04 \\
(.02)\end{array}$ & & & \\
\hline $\begin{array}{l}\text { Expenditures } \\
\text { per Capita }\end{array}$ & $\begin{array}{l}.55 \\
(.06)\end{array}$ & $\begin{array}{l}-.12 \\
(-.36)\end{array}$ & & \\
\hline Price (with Credit) & $\begin{array}{l}.24 \\
(.37)\end{array}$ & $\begin{array}{l}-.60 \\
(-.16)\end{array}$ & $\begin{array}{l}.09 \\
(.00)\end{array}$ & \\
\hline $\begin{array}{l}\text { County (Individual) } \\
\text { Property Tax Rate }\end{array}$ & $\begin{array}{c}.61 \\
(-.01)\end{array}$ & $\begin{array}{l}-.52 \\
(-.13)\end{array}$ & $\begin{array}{l}.47 \\
(.16)\end{array}$ & $\begin{array}{c}.39 \\
(-.13)\end{array}$ \\
\hline
\end{tabular}

NOTE: For 38 countries with $N>10$ (for 1129 individuals).

See Appendix for definitions.

consistent, but one thing that is clear is that the smallest percentage price reductions occur in counties with below-average income and property tax base per capita. On the other hand, Oakland, the highest income county, with a substantial property tax base and substantial public spending, faces an above-average reduction in tax price. Thus the incentive to spend more is, if anything, likely to be positively related to the income of the community - an unsettling result if one's objective is to stimulate spending in low-income, low-spending areas.

All of the conclusions that one might reach from Table 4 must be taken as tentative, if only because the data represent county means rather than observations about individuals within the county. This is a particular problem when one is discussing the effect of the circuit-breaker on tax price, an effect that is felt very unevenly by households within a jurisdiction. This can be seen by examining Table 5, which includes some of the simple correlations between a number of relevant policy variables, calculated first using the county means for all counties with a sample of ten or more households and second for all homeowners within the circuit-breaker sample. 
Note first that tax base per capita is positively correlated with income at the micro level and negatively correlated with income when county data are used. This may be due in part because lower tax base, high-income counties tend to have a much higher tax rate than do their low-income counterparts. ${ }^{16}$ This corresponds to a similar result cited by Inman and Rubinfeld (1979) and supports our negative conclusions about the circuit-breaker for a number of reasons. First, the cost of achieving redistribution is not small in terms of budgetary outlays made by the state. Second, the income distributional consequences of the program as designed may never be achieved in practice because of the failure of eligible participants to claim their credits. Finally, while the circuitbreaker will tend to reduce tax prices, (a) voters do not perceive those reductions, and (b) the reductions are greatest in those communities with relatively high income and local spending. Thus if one takes as an ancillary goal the increased spending of low-income, low-spending jurisdictions, the circuit-breaker may be a costly and rather ineffective program.

APPENDIX 1

Variable Definitions

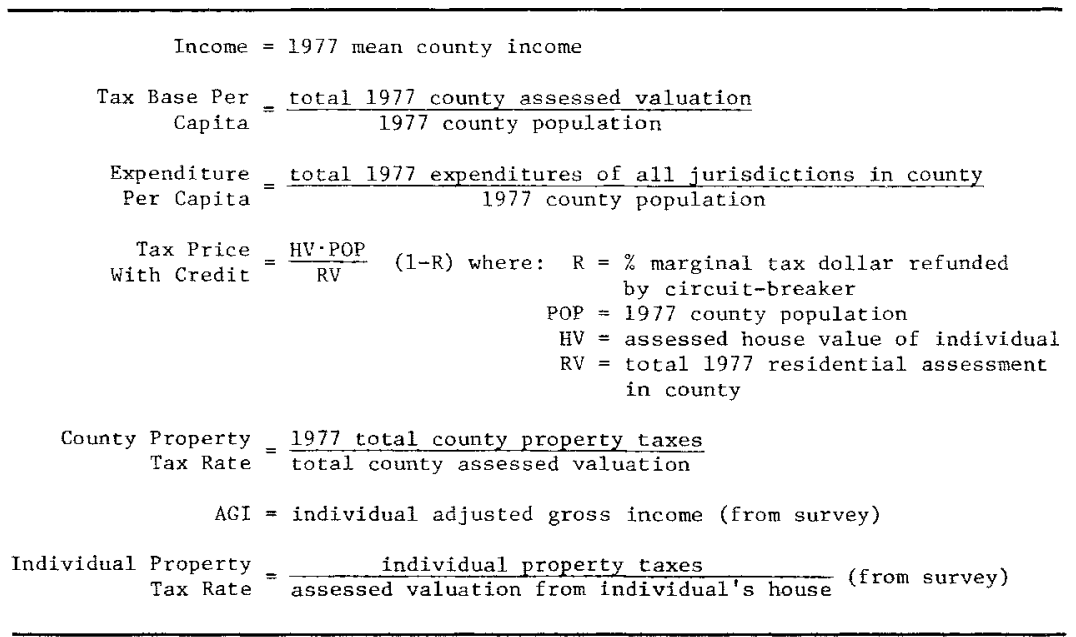




\section{NOTES}

1. There were 338 households that did not answer the question concerning household income. We were able to assign predicted income values for all but 53 of these households by using a multiple regression model to arrive at predicted income values. The model was estimated from the rest of the sample and used the following predictors of income: race, age, education, occupation, sex of head, and hours employed by head and wife. No assignment was given to those who failed to answer any of the questions used to create the predictor variables. For more on the survey design and its purpose, see Courant et al. (1979).

2. We were not able to calculate rebates for 228 of the 2001 households because of nonresponse on such key variables as house value, income, or homeownership status.

3. As far as we can tell the $17 \%$ attempts to account for the shifting of the tax on renters and is based on Netzer (1966, p. 28).

4. Over 3.4 million Mi-1040 state income tax returns were filed in 1977. Property tax collection totaled $\$ 2$ billion in 1976 . Circuit-breaker data taken from published state figures based on a $10 \%$ sample of state income tax returns.

5. Some $43 \%$ of our sample reported filing for the circuit-breaker (the state sample reported $33.8 \%$ filing). The $43 \%$ clearly contains some respondents who were not eligible to receive a credit (by our calculations), and thus leads to a higher estimate of participation and a lower estimate of average benefit ( $\$ 161$ per capita). High response participation rates are consistent with voter survey findings (see Traugott and Katosh, 1979). Because of this and other technical problems involving data comparability over time, we use the response to the filing question only to get a sense of how participation rates vary among households.

6. The general problem of program participation and eligibility and its distributional consequences is identified by Bendick (1974).

7. The Michigan State analysis also shows larger rebates to high-income filers. Gold (1979) reports that the percentage of households qualifying for the circuit-breaker falls as income rises. Of course, reporting progressivity may be muted if we take a life-cycle view of housing consumption. Those with current high incomes may have lower average incomes, and vice versa.

8. The term "regressive" here is used only to measure the direct relationship between taxes and current income. We wish to make no further presumption about the true "incidence" of the property tax. Whatever that incidence may be, our empirical results suggest the relationship between changes in the circuit-breaker and changes in that incidence. For further discussion of the measurement of the incidence of the property tax with a focus on the distinction between current and permanent income, see Ihlanfeldt (1979), Aaron (1975), and Netzer (1973). The different elasticity values for homeowners and renters reflect, in part, different mean income levels for two groups. However, since the conditions for progressivity or regressivity do not change, our conclusions within homeownership/renter class are not affected.

9. We assume that the formula for those over 65 does not change.

10. Our presumption is that such reforms were not put into effect for political reasons.

11. We reiterate that proportionality is chosen for the purpose of this example, but that it does not necessarily have any particular normative significance. Note also that our regressions are ad hoc, not taking into account general equilibrium effects on consumption and public services. 
12. Our derived schedules for $p$ and $\mathrm{t}$ do little for renters. This is because the schedule is based upon the relationship we estimated for homeowners

$$
\frac{d \frac{T}{Y}}{d Y} \text {. }
$$

Our attempts at deriving this simple relationship for renters never explained more than $2.6 \%$ of the variance.

13. We assume a model in which the circuit-breaker can change the tax price of the decisive voter (see Inman, 1978).

14. Tax prices appear large in this table because they are based on households. Our tax price measures the cost of raising an additional dollar of per capita expenditure and therefore must be multipled by household size. The median size of a Michigan household is nearly 3.4 , causing tax prices to exceed, on average, 1. Sample characteristics can account for additional tax price variance.

15. We have reason to believe that the price elasticity of demand for public services is substantially below unity. For a summary of the evidence, see Inman and Rubinfeld (1979); for some recent evidence, see Gramlich and Rubinfeld (1982). Note also that the impact of the price change on the median voter has been presumed to equal the mean price change felt by all households. Failure of this assumption to hold may bias the results, but we cannot tell in what direction that bias might be.

16. These communities may also have a greater taste for public services.

\section{REFERENCES}

AARoN, H. J. (1975) Who Pays the Property Tax-A New View. Washington, DC: Brookings Institution.

(1974) "What do circuit breaker laws accomplish?" in G. E. Peterson (ed.) Property Tax Reform. Washington, DC: Urban Institute.

BENDICK, M., Jr. (1974) “Designing circuit-breaker tax relief." National Tax J. (March): 19-28.

COURANT, P. N., E. M. GRAMLICH, and D. L. RUBINFELD(1979) "Tax limitation and the demand for public services in Michigan." National Tax J. 32 (June): 147-157.

GOLD, S. D. (1979) Property Tax Relief. Lexington, MA: D. C. Heath.

___ (1976) "A note on the design of property tax circuit-breakers." National Tax J. 29 (December): 477-481.

GRAMLICH, E. M. and D. L. RUBINFELD (1982) “Micro estimates of public spending demand functions and tests of the tiebout and median-voter hypotheses." $J$. of Political Economy 90: 536-560.

GRUBB, W. N. and E. G. HOACHLANDER (1978) "Circuit-breaker schedules and their application in California." Policy Analysis 4 (Summer): 317-338.

IHLANFELDT, K. R. (1979) "The incidence of the property tax on homeowners: evidence from the panel study of income dynamics." National Tax J. 32 (December): 535-542.

INMAN, R. P. (1978) "Testing political economy's 'as if" proposition: is the median income voter really decisive?" Public Choice 33: 45-65.

___ and D. L. RUBINFELD (1979) "The judicial pursuit of local fiscal equity." Harvard Law Rev. 92 (June): 1662-1750. 
Michigan, State of (1977) "Analysis of the Michigan Individual Income Tax for 1977." Lansing, MI: Department of Treasury.

NETZER, D. (1973) "The incidence of the property tax revisited." National Tax J. 26 (December): 515-535.

- (1966) Economics of the Property Tax. Washington, DC: Brookings Institution.

POLINSKY, A. M. and D. T. ELLWOOD (1979) “An empirical reconciliation of micro and grouped estimates of the demand for housing." Rev. of Economics and Statistics 61 (May): 199-205.

RUBINFELD, D. L. (1977) "Voting in a local school election: a micro analysis." Rev. of Economics and Statistics 59 (February): 30-42.

SHROEDER, L. D. and D. L. SJOQUIST (1978) "Alternative circuit breaker programs: an analysis of the size and distribution of benefits." Public Finance Q. 6 (October).

TRAUGOTT, M. W. and J. P. KATOSH (1979) "Response validity in surveys of voting behavior." Public Opinion Q. 43: 359-377.

U.S. Advisory Commission on Intergovernmental Relations [ACIR] (1979) Significant Features of Fiscal Federalism 1978-79. Washington, DC: Government Printing Office.

___ (1975) Property Tax Circuit-Breakers: Current Status and Policy Issues. Washington, DC: Government Printing Office.

Daniel L. Rubinfeld is currently Professor of Economics and Law at the University of Michigan, Ann Arbor, Michigan. He has written in the subject areas of local public finance, econometrics, and law and economics.

Michael J. Wolkoff is currently Assistant Professor of Political Science at the University of Rochester, Rochester, New York. He has written in the subject areas of local and urban public finance. 